\title{
Effect of starch sizes particle as binder on short pineapple leaf fiber composite mechanical properties
}

\author{
Mohd Zulkefli Selamat ${ }^{1, *}$, Muhammad Syazwan Zhafri Tahir ${ }^{1}$, Ayu Natasya Kasim $^{1}$, Sivakumar Dharmalingam ${ }^{1}$, Azma \\ Putra $^{1}$, Mohd Yuhazri Yaakob ${ }^{1}$ and Mohd Ahadlin Mohd Daud ${ }^{1}$ \\ ${ }^{1}$ Centre of Advanced Research on Energy (CARe), Faculty of Mechanical Engineering, Universiti Teknikal Malaysia Melaka, Hang \\ Tuah Jaya, 76100 Durian Tunggal, Melaka, Malaysia.
}

\begin{abstract}
Pineapple leaf fiber (PLF) is one of the natural fibers that abundantly can be found in Malaysia, but the usage of the pineapple plant is limited only on their fruit and the other parts to be a waste. In this study, PLF is used as the reinforcement material and starch ( $\mathrm{SH})$ used as the matrix or binder. Both materials were combined with several compositions ratio (weight percentage) of PLF/SH composites which are $50 \mathrm{PLF} / 50 \mathrm{SH}, 60 \mathrm{PLF} / 40 \mathrm{SH}$ and $70 \mathrm{PLF} / 30 \mathrm{SH}$. Before undergo the fabrication process, the fiber has gone through an alkaline treatment to increase the strength of the fiber and chopped with an approximate size range from $0.5 \mathrm{~mm}$ to $5 \mathrm{~mm}$. Besides that, SH powder is sieved to gain several particulate sizes which are $75 \mu \mathrm{m}, 100 \mu \mathrm{m}$ and $250 \mu \mathrm{m}$. The related tests such as flexural, hardness, density tests and macrostructure analysis have been done to determine their mechanical properties of composite. Based on the results, the sample with composition of 70PL/30SH with $75 \mu \mathrm{m}$ has shown the highest result for flexural stress which is $14.49 \mathrm{MPa}$. While, the composite with the same composition of 70PLF/30SH with particulate size SH of $250 \mu \mathrm{m}$ has shown the highest result in the hardness of 67 Shore-D and density of $1.36 \mathrm{~g} / \mathrm{cm} 3$ respectively.
\end{abstract}

\section{Introduction}

A composite is a material that combined from two or more materials to produce a new material that has a new or improved ability from its original individual components [1-2]. Basically most of the materials that exist or we see is made of a composite materials. For examples, bones, wood, and stone are natural composite items that develop by a natural process. The leaf itself consist of natural fibre and usually use in making a new composite materials because of their unique characteristics which have good mechanical properties, stronger, lighter, biodegradable and less expensive compared to the synthetic fibre. Because of that, natural fibres have huge potential to be an alternative to synthetic fibres such as the glass fibre and carbon fibre [3-4].

There are a few examples of natural fibres that can be extracted from a plant such as pineapple leaf, palm leaf, banana leaf, hemp, kenaf, bamboo and coconut shell fibre [4]. From all natural fibres, pineapple leaf fibre (PLF) seems to have the highest cellulose content which makes the fibres can produce good mechanical properties. In order to give the unique ability for the natural fibres, binder/matrix such as the starch, epoxy and polypropylene are added to enhance the existing mechanical properties or called as a reinforcement of a material. In other words, reinforcement is strengthening the structure or material itself. For an example, back in the ancient years, clay was reinforced by straw to build walls. In this case, clay will become the binder holding the straw together thus; make the construction become stronger [5-6].

As the previous studies shown that fibre-reinforced plastic (FRP) is a very well-known composite that being used in structure engineering like mostly in the field of aerospace, buildings and also offshore platforms as they are considered to have more strength, non-corrosive, light in weight and are easily moulded or constructed. But the materials or fibres are usually from the glass and carbon combining with the plastic polymer as the binder [7]. While in this study, PLF will be used as the reinforce material and starch as the binder or the matrix which may potentially give a good result in mechanical properties besides it characteristics which is an environmental friendly, renewable, recyclable and biodegradable.

Nowadays, the implementations of natural fibres are still in research phase. Some of the problems arise is that synthetic fibres is widely use are hardly to decompose and are not sufficiently eco-friendly. Using natural fibres will allow many environmental problems to be solved. The combination of natural fibres such as pineapple leaf, kenaf, hemp and jute fibres with certain type of binder/matrix to produce a composite materials seems can be compete with existing synthetic composites which they have a good mechanical properties [8-10]. Recently, natural fibres have been

* Corresponding author: zulkeflis@utem.edu.my 
awakening the industry to substitute their products by using the natural composite has been widely use in the automotive industry. Thus, because by using the natural fibres they can produce a higher strength of automotive interior components but cheaper in price [11-14]. Biodegradable composite can be defined as composite material or the combination between matrix and reinforcement of natural fibres. These kinds of materials have their own function which keep strengthening the properties of the matrix that was used, but always providing biodegradable compatibility. The constituents inside the bio-degradable composite consist of reinforcement from natural fibre and matrix from natural polymer. Bio-degradable composite totally comply with the green composite concept where all the material are from natural source [15-17]. Bio-degradable composite become prominent product since it is eco-friendly and safe too human application. It is also known as composite material made from natural fibre and polymer matrix derived from petroleum such as polylactic acid (PLA), cellulose and thermoplastic starch [18-20] (Sahari \& Sapuan, 2011). Thus, the matrix part of the biodegradable composite can be classified into two parts which are fully degradable and partly degradable as shown in Figure 1.

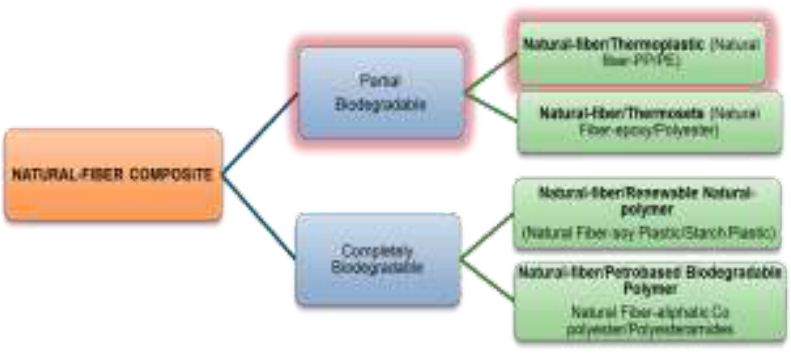

Fig.1. The classification of biodegradable composite [21]

In this project, the pineapple leaf fibre (PLF) is chopped with the range of size approximately from 0.5 up to $5 \mathrm{~mm}$ was used as the reinforce material as the fiber orientation as if the composite material will be the random-discontinuous, while starch as the binder and the difference particulate size of starch range from 75, 100 and $250 \mu \mathrm{m}$ are used to produce the PLF/SH composite. The composite will be tested to determine the mechanical properties of the material. The related tests done will be based on the American Standard Testing Method (ASTM) and by referring the previous studies. The tests that will be covered or done are the hardness test, density test, fractured strength test and macrostructure analysis. The composite seems to have a good potential that can be widely use in the industry like for example for the plastic industries product that can provide more benefit to the environment.

\section{Methodology}

This research is studies the effects PLF loading on the mechanical properties of PLF/SH composite. The various ratio of $\mathrm{PLF} / \mathrm{SH}$ composite were been selected and the ratio of composition were fixed as shown in Table 1. The materials used in the fabrication of FRP composites are PLF and SH. Figure 2 (a) and (b) shows the image of PLF and ST. Meanwhile, Table-2 shows the specific mechanical properties of various PLF types. An alkaline treatment has be conducted to extract the pineapple leaf bundles and enhance the pineapple leaf properties. After that the PLF is chopped into smaller size with the approximate in the range size of 0.5 up to 5 $\mathrm{mm}$ and starch is sieved to gain several sizes of particulate from which are 75, 100 and $250 \mu \mathrm{m}$ before the formation process of PLF/SH composite by using hot press. The mechanical properties of pineapple leaf-starch composite will be determined by using flexure test, hardness test, density measurement and macrostructure analysis.

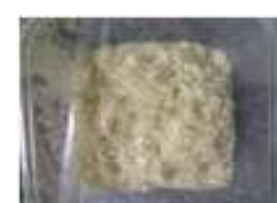

c

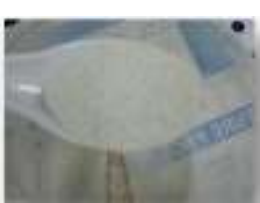

b
Fig.2. (a) Chopped PLF and (b) SH powder

Table 1. Composition of PLF/SH composite

\begin{tabular}{|c|c|c|}
\hline PLF (wt $\%)$ & SH size particle $(\mu \mathrm{m})$ & SH (wt \%) \\
\hline \multirow{3}{*}{50} & 75 & \multirow[t]{3}{*}{50} \\
\hline & 100 & \\
\hline & 250 & \\
\hline \multirow[t]{3}{*}{60} & 75 & \multirow[t]{3}{*}{40} \\
\hline & 100 & \\
\hline & 250 & \\
\hline \multirow[t]{3}{*}{70} & 75 & \multirow[t]{3}{*}{30} \\
\hline & 100 & \\
\hline & 250 & \\
\hline
\end{tabular}

Table 2. Types of pineapple cultivars and physical properties [13]

\begin{tabular}{|l|c|c|c|}
\hline \multicolumn{1}{|c|}{ Properties } & \multicolumn{3}{|c|}{ Cultivar } \\
\cline { 2 - 4 } & Moris Gajah & Josapine & Sarawak \\
\hline $\begin{array}{l}\text { Average no. of } \\
\text { leaves }\end{array}$ & 50 & $65-70$ & $65-70$ \\
\hline $\begin{array}{l}\text { Length of leaves } \\
(\mathrm{mm})\end{array}$ & 63 & 61 & 70 \\
\hline $\begin{array}{l}\text { Width of leaves } \\
(\mathrm{mm})\end{array}$ & 61 & 46 & 65 \\
\hline $\begin{array}{l}\text { No. Of fiber } \\
\text { bundles per leaf }\end{array}$ & 90 & 80 & $>100$ \\
\hline Diameter $(\mu \mathrm{m})$ & $120-440$ & $105-300$ & $170-340$ \\
\hline
\end{tabular}

\section{Results And Discussion}

\subsection{Effect of particulate size of SH in PLF/SH composite with different composition on Flexure Stress}

The flexural properties of the composites material are shown in Figure 3. The results shows based on the different composition from 50PLF/50SH, 60PLF/40SH to $70 \mathrm{PLF} / 30 \mathrm{SH}$ with each composition contain of different sizes of particulate size of $\mathrm{SH}$ which are from $75 \mu \mathrm{m}, 100 \mu \mathrm{m}$ and $250 \mu \mathrm{m}$. Based on previous study, 
the higher the fiber content in a composite material, the stronger the mechanical properties will be [6].

Figure 3 shows the comparison for all nine samples of the composite materials. Based on the loading of PLF, the flexural stress is decreased with the increment of SH particle size for all composition. Meanwhile in general, the trend was found that the flexural stresses are gradually increased as the composition of the PLF content was increased. This can be compared by same particulate size of the starch, SH that $50 \%$ content of PLF in the $75 \mu \mathrm{m}$ is only gained $8.17 \mathrm{MPa}$. The result increasing as the PLF content rose to $60 \%$ and the flexural stress shows result of $11.69 \mathrm{MPa}$. The results substantially increased to $14.49 \mathrm{MPa}$ as the PLF content keep rising until $70 \%$. The results obtained from this experiment are compatible with the results that had been found by Selamat (2016) which used short PLF with the length of $2 \mathrm{~cm}, 4 \mathrm{~cm}$ and $6 \mathrm{~cm}$ with a matrix of SH. The results of the findings show that the higher the fiber content also will gradually increase the value of the flexural stress.

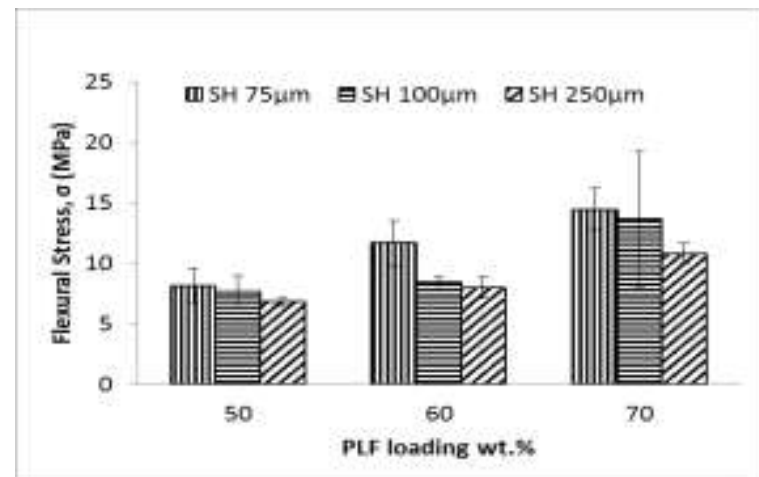

Fig. 3. The Flexural Stress with various PLF loading and size of particle

Instate of composition of the fiber and binder/matrix, this research also highlight about the different sizes of the binder in the composite material whether it will gives a significance results on the mechanical properties or not. Based on Figure 3, it shows that the finest size of binder will gives the higher value in flexural stress of the composites material itself. This is due to the ability of the binder as a thermoplastic to react and melted with heat faster as it being pressed makes it hold to the fiber firmly and thus make the mechanical properties went stronger [22]. This experiment is repeated a few times and the average results is then been calculated. This is to obtain more accurate results as the sample might have some discontinuities during to the fabrication process as it shows random error bars in the results. This is due to the smaller particle SH sizes that will lead to be more even dispersion, thus make the flexure stress to be stronger.

\subsection{Effect of particulate size of $\mathrm{SH}$ in PLF/SH composite with different composition on Hardness}

Based on Figure 4, the graph shows the results of the hardness (Shore-D) with the various percentage of
PLF content and the sizes of particulate SH respectively. The results show that the hardness increases with the increment of the fiber loading and the particulate size of the binder materials for all the samples. The experiment had been repeated at several points to more accurate results.

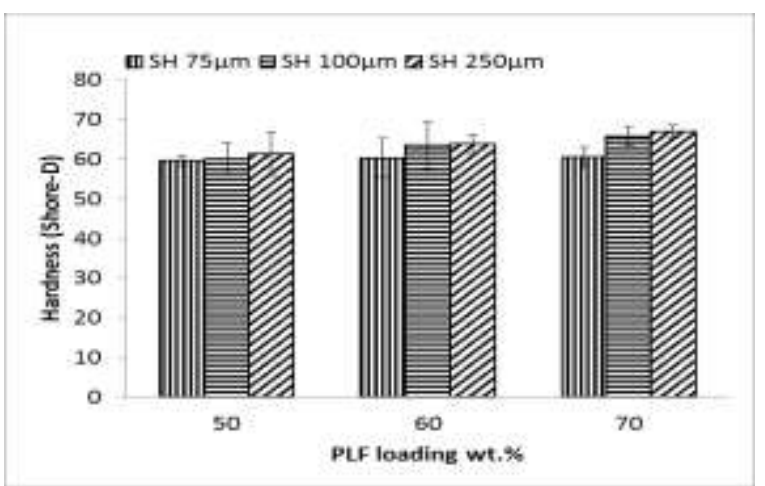

Fig. 4. The Hardness (Shore-D) with various PLF loading and size of particles

The result obtained for the $75 \mu \mathrm{m}$ shows a small increment of $1.34 \%$ in results for the composition of $50 \mathrm{PLF} / 50 \mathrm{SH}$ to $60 \mathrm{PLF} / 40 \mathrm{SH}$ and increasing $5.79 \%$ for the 70PLF/30SH composition of the composite material. Since the reinforcement material is in the random discontinuous orientation, it leads to uneven dispersion of the matrix. In other words, the higher the matrix content it makes it harder for the PLF to mix well with the SH. Hence, make the sample with the larger content of PLF give the highest value of hardness compare to the lower amount of PLF composition of the composite material [23].

Meanwhile, at the composition of $60 \mathrm{PLF} / 40 \mathrm{SH}$ with the particulate size of $100 \mu \mathrm{m}$ and $250 \mu \mathrm{m}$ show a very small difference of hardness which is 63.6 and 63.8 in values. For fiber loading, it can be seen clearly that, with the highest content of fiber loading $70 \%$, has shown the highest value of 67 of hardness. The declination of the results may due to the unsmooth surface or the matrix and the fiber are not properly mix during the fabrication process and make the material does not melt properly. Thus, the sample cannot withstand the wear resistance of the composites. This is the reason why the experiment has to be repeated for a several times as the error bars showed on the graph indicates the ability of the maximum and minimum hardness value for the composite material to withstand any wear resistance. In a research by Selamat and Mashitah (2015) the materials used are PLF for the reinforcement material and $\mathrm{SH}$ as the binder. The results shows a abreast result with the results obtained from this experiment which proved that the higher PLF content will slightly rose the results of the hardness test.

\subsection{Effect of particulate size of $\mathrm{SH}$ in PLF/SH composite with different composition on density}

Based on the data of Density $(\mathrm{g} / \mathrm{cm} 3)$ vs. PLF Loading (\%) as shown in Figure 4, the lowest density is 
in $50 \%$ fiber loading with $250 \mu \mathrm{m}$ size of SH. The bar chart on the $50 \%$ fiber loading shows a same value of density at $75 \mu \mathrm{m}$ and $100 \mu \mathrm{m}$ which is $1.292 \mathrm{~g} / \mathrm{cm} 3$ but fall dramatically when the size of $\mathrm{SH}$ increased to 250 $\mu \mathrm{m}$ with a density value of $1.166 \mathrm{~g} / \mathrm{cm} 3$.

Figure 5 also shows that the increasing in fiber loading and the size of matrix will increase the density measurement of the samples. This can be seen clearly at the composition of $60 \%$ and $70 \%$ which shown the data collected to be slightly grown as the size of $\mathrm{SH}$ increased. This can be concluded that the density of the composite material is directly proportional to the fiber loading and size of the matrix materials, in this case is starch. In this research it is proved that the percentage of fiber loading and the size of the matrix will affect the density measurement of the composite material.

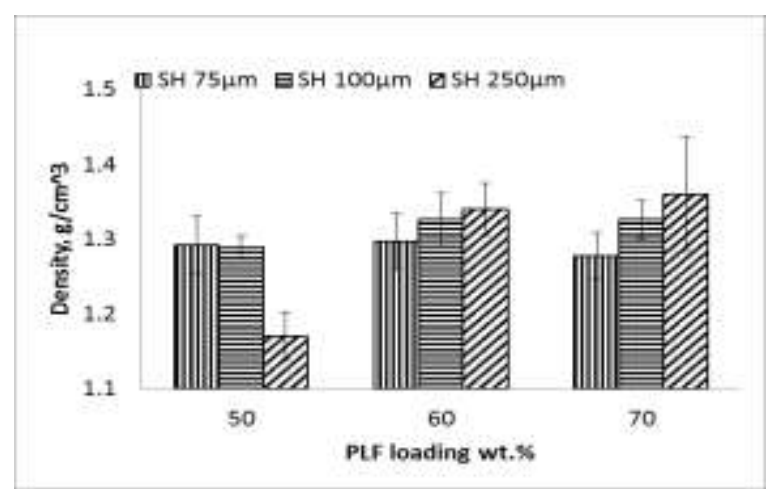

Fig. 5. The Density of various PLF loading and size of particles

In this case, the highest density is found at the 70PLF/30SH composition is because of the ability of the starch to fully melt as it is in fewer composition. This make the $\mathrm{SH}$ is fully covered the PLF, thus make it less water absorption through the samples. To make sure the results is acceptable, the test is repeated with three different specimens for each samples and the average data is taken out as the comparison among all other sample with different composition and particulate size of $\mathrm{SH}$.

The error bar data shows that each of samples with different content of fiber loading can be rises and drop up to the indicated values of the error. If the value is above or less that the indicated standard deviations, it means that the results is not acceptable and the experiment is failed. To avoid this, the experiment can be repeated with more specimen and make sure all the dimensions of the specimens is the same as it may affect the result and the absorption of water if they have a different dimensions.

\subsection{Macrostructure Analysis}

Based on Figure 6 it shows all the macrostructure analysis for all the composition based on the percentage of fiber content and also the size of the matrix materials. The sample that with higher composition of SH tends to have voids compare to the one who has less SH content. This is may cause from the higher level of matrix make them hardly to be mix properly and the probability for the SH to accumulate at a certain spot is much higher. Thus, make the SH more difficult to melt and this make the bonding is weaker between the fiber and matrix. This result is contradicted with the composition of 70PLF/30SH which previews a very good surface of composite materials with no voids at all.

Fig. 6. Microstructure of PLF/SH composites

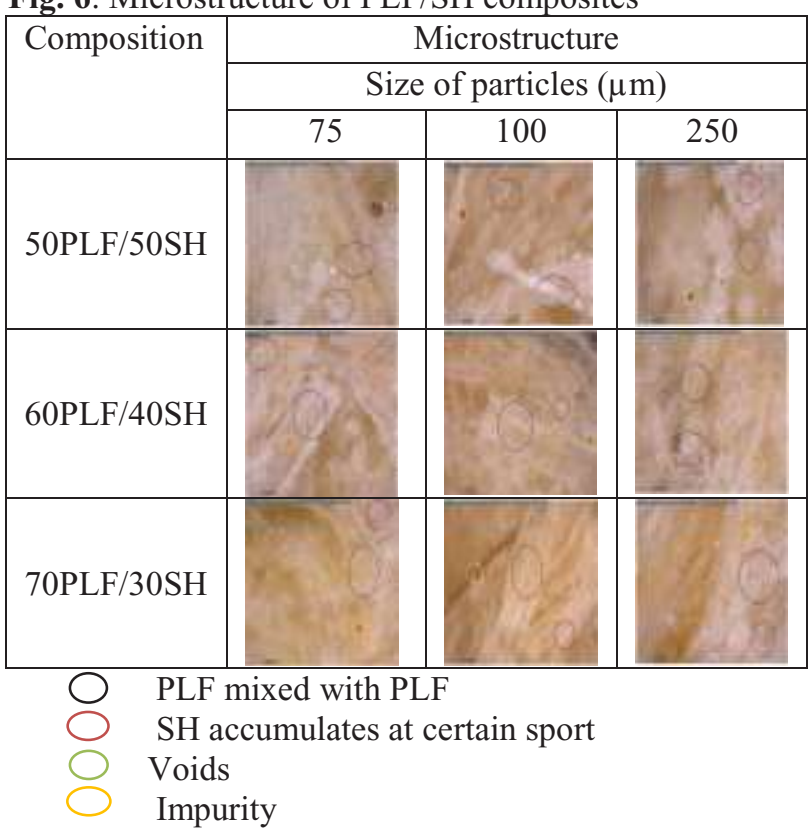

For the size of particulate $\mathrm{SH}$, it seems that the finer size will contribute a much better surface compare to those with larger size of particulate $\mathrm{SH}$. The sample that fabricated from $75 \mu \mathrm{m}$ of SH shows a good adhesion between chopped PLF and SH with a clean surface and minor presence of impurities compared to $100 \mu \mathrm{m}$ and $250 \mu \mathrm{m}$. This shows that the finest size of SH is easier to be mix with the chopped PLF and will be melt evenly making a stronger bonding between the fiber and also the matrix material $[8,24]$. Thus, this contributed a big part in affecting the mechanical properties of the composite material.

\section{Conclusion}

This research is basically the studies on how to produce a natural composite which is formed by a combination of natural fiber and natural polymer. This green composite material basically can be used in the plastic industries. Pineapple leaf fiber is used as the reinforcement material while starch is used as the matrix or binder. The main objective of this research is to study the effect of pineapple leaf fiber with the difference particulate sizes of starch on the composite material mechanical properties. The expected result that may be obtained from this project is the finer size of the particulate matrix may have a greater value in the mechanical properties compared to the larger size of the particle. From the results obtained in this research, the mechanical properties have showed that these biodegradable materials can be useful in the production of composite material. Based on the flexural test, it can 
be concluded that the higher percentage of fiber content which is $70 \%$ will give the highest value of $14.49 \mathrm{MPa}$ of flexural stress with the finest size of SH. This result is in line with the expected result of this research. In the hardness test also shows an interesting results, where a sample with composition of $70 \mathrm{PLF} / 30 \mathrm{SH}$ give the greatest hardness with value of 67 Shore-D. Based on these findings, it can be concluded that the fiber loading will affect the mechanical properties of the composites material itself. Besides that, it can be conclude that the finest size of the matrix will give an advantage base on the ability to be mixed properly with the fiber and also easier to be melt in the fabrication process. Thus, this also gives a hint that the finer size of matrix will be a good potential in producing a higher performance of the composite material of PLF/SH.

\section{Acknowledgement}

The authors would like to thank the Malaysia Ministry of Higher Education, Malaysia Ministry of Science, Technology and Innovation for sponsoring this work under Grant FRGS/2/2014/SG06/FKM/02/F00237 and Advanced Material Research Group (A-MAT), Faculty Mechanical Engineering, University Teknikal Malaysia Melaka (UTeM) for financially sponsoring, facilities and gratefully knowledge during this research.

\section{References}

1. Siva N, Paul J. J, Fabrication and Experimental Analysis of Pineapple Leaf Fiber Based Composite Material, 243246. (2015)

2. 5980 Floor Model Systems for High-Capacity Universal Testing. (n.d.). Retrieved December 11,( 2015)

3. Liu W, Misra M, Askeland P, Drzal L. T, Mohanty A. K,.'Green' Composites from Soy Based Plastic and Pineapple Leaf Fiber: Fabrication and Properties Evaluation, 1-3 (2005)

4. R.Jumaidin, S.M. Sapuan, M. Jawaid, M.R. Ishak and J.Sahari. Characteristic of thermoplastic suger plam Starch/Agra blend : Thermai, tensile and physical properties. International Journal of Biologcal Macromolecules, 89, 575-581 (2016)

5. Drzal L. T, Mohanty A. K, Misra M,. Bio-Composite Materials as Alternatives to Petroleum-Based Composites for Automotive Applications, 1-7 (2009)

6. Mohd Zulkefli Selamat, Mashita Razi, Ayu Natasya Kasim, Sivakumar Dharmalingam, Azma Putra, Mohd Yuhazri Yaakob and Mohd Ahadlin Mohd Daud. Mechanical Properties of Starch Composite Reinforced by Pineapple Leaf Fibre (PLF) from Josapine Cultivar, ARPN Journal of Engineering and Applied Sciences, 9783-9788 (2016)

7. Wambua, P., Ivens, J. and Verpoest, I.. "Natural fibers: Can they replace glass in fiber reinforced plastics?", Composites Science and Technology 23,1259-1264. (2003)

8. Masuelli M. A, (2013). "Introduction of Fibre-Reinforced Polymers - Polymers and Composites: Concepts, Properties and Processes", 14 Oct, (2015)

9. Arib, R., Sapuan, S., Ahmad, M., Paridah, M., \& Zaman, H.. "Mechanical properties of pineapple leaf fibre reinforced polypropylene composites". Materials \& Design, 391-396 (2004)
10. Selamat MZ, Sahari J, Muhamad N, Muchtar A. THE EFFECTS OF THICKNESS REDUCTION AND PARTICLE SIZES ON THE PROPERTIES GRAPHITE POLYPROPYLENE COMPOSITE. International Journal of Mechanical and Materials Engineering (IJMME), Vol.6 (2011), No.2, 194-200

11. Bledzki AK, Gassan J. "Composites reinforced with cellulose based fibers". Prog Polym Sci; 24(2), 221-74. (1999)

12. Dhal, J., \& Mishra, S. "Processing and Properties of Natural Fiber-Reinforced Polymer Composite". Journal of Materials, 1-6 (2012)

13. Dagade P.C. Shaikh S. M, "Fabrication of Composite Materials by using Short Pineapple Leaf Fiber (PALF)", IJIERT Journal, 2 (2015)

14. Nabilah A.. "Effect of Pineapple Leaf Fiber Loading on the Properties of Pineapple Leaf Fiber-Polypropylene Composite", Thesis UTeM, 44-51(2014)

15. Mohamed A.R., Sapuan S.M, Shahjahan M, Khalina A, "Characterization of pineapple leaf fibers from selected Malaysian cultivars". (2008)

16. Kasim, A.N, Selamat, M.Z, Aznan, N., Sahadan, S., Daud, M.A.M, Salleh, S. \& Jumaidin, R. Effect of pineapple leaf fiber loading on the properties of pineapple leaf fiberpolypropylene composite. Jurnal Teknoloy. 21, 117-123 (2015)

17. Kasim, A.N., Selamat, M.Z., Daud, M.A.M., Yaakob, M.Y., Putra, A. \& Sivakumar, D.. Mechanical properties of polypropylene composites reinforced with alkaline treated pineapple leaf fibre from Josapine cultivar. International Journal of Automotive and Mechanical Engineering. 13, 3157-3167 (2016)

18. Selamat, M.Z., Kasim, A.N., Shamsudin, S.A., Mohd Daud, M.A. \& Dhar, S. Effect of Bamboo Fibre Length on The Mechanical Properties of Bamboo Fibre/Polypropylene Composite. 8th MUCET (2014)

19. Selamat, M.Z., Razi, M., Kasim, A.N., Sivakumar, D.M., Azma, P., Daud, M.AM. \& Yuhazri, Y. Mechanical properties of starch composite reinforced by pineapple leaf fiber (PLF) from josapine cultivar. ARPN Journal of Engineering and Applied Sciences. 11(16) 9783-9788 (2016)

20. Mohamed, A.R., Sapuan, S.M., \& Khalina, A. Selected properties of hand-laid and compression molded vinyl ester and pineapple leaf fiber (PALF) reinforced vinyl ester composites. International Journal of Mechanical and Materials Engineering. 5(1), 68-73 (2010)

21. Abdul Khalil, H.P.S., Bhat, I.U.H., Jawaid, M., Zaidon, D.Hermawan, A., Hadi. Y.S. 2012. Bamboo Fiber Reinforced Biocomposites: A review. Materials and Design. 42, 353-368 (2012)

22. Kalapakdee, A. \& Amornsakchai, T. 2014. Mechanical properties of preferentially aligned shortpineapple leaf fiber reinforced thermoplastic elastomer: Effects of fiber content and matrix orientation. Polymer Testing 37, 3644.

23. George, J., Bhagawan, S. S., Prabhakaran, N. S. \& Thomas, S. Short pineapple-leaf-fiber-reinforced low-density polyethylene composites. Journal of Applied Polymer Science. 57, 843-854 (1995)

24. Luo, S. \& Netravali, N. Mechanical and thermal properties of environment-friendly "green" composites made from pineapple leaf fibres and poly (hydroxybutyrate-co-valerate) resin. Polym Compos. 20, 367-78 (1999) 